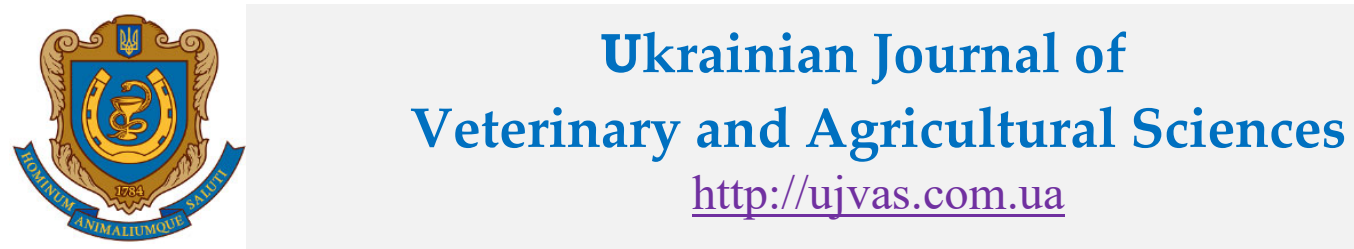

Stepan Gzhytskyi National University of Veterinary Medicine and Biotechnologies Lviv

\begin{tabular}{l|l|l} 
original article & UDC 619:576.895.1:636.2 $\quad$ doi: 10.32718/ujvas4-2.09
\end{tabular}

Volume 4

Number 2

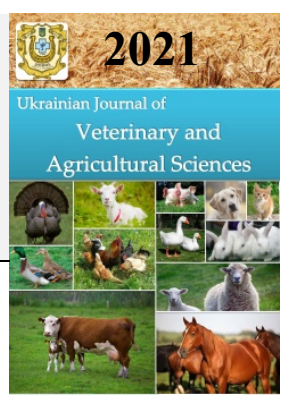

\title{
The comparative evaluation of complex drugs based on fipronil for ectoparasitosis of dogs and cats
}

\author{
O. L. Tishyn ${ }^{1}$, I. D. Yuskiv ${ }^{1,2}$, L. L. Yuskiv ${ }^{2}$, Zn. M. Perih ${ }^{1}$, O. M. Bogach ${ }^{1}$ \\ ${ }^{I}$ State Scientific-Research Control Institute of Veterinary Medicinal Products and Feed Additives, Donetska Str., 11, Lviv, \\ 79019, Ukraine
}

${ }^{2}$ Stepan Gzhytskyi National University of Veterinary Medicine and Biotechnologies, Pekarska Str., 50, Lviv, 79010, Ukraine

\begin{tabular}{|c|c|}
\hline \multicolumn{2}{|l|}{$\begin{array}{l}\text { Article info } \\
\text { Received 09.07.2021 } \\
\text { Received in revised form } \\
\quad 16.08 .2021 \\
\text { Accepted 17.08.2021 }\end{array}$} \\
\hline \multirow{2}{*}{\multicolumn{2}{|c|}{$\begin{array}{l}\text { Correspondence author } \\
\text { Igor Yuskiv } \\
\text { Tel.: +38-063-223-36-22 } \\
\text { E-mail: igor_yuskiv@ukr.net }\end{array}$}} \\
\hline & \\
\hline \multicolumn{2}{|c|}{$\begin{array}{l}2021 \text { Tishyn O. et al. This is an } \\
\text { open-access article distributed under } \\
\text { the terms of the Creative Commons } \\
\text { Attribution License, which permits } \\
\text { unrestricted use, distribution, and } \\
\text { reproduction in any medium, } \\
\text { provided the original author and } \\
\text { source are credited. }\end{array}$} \\
\hline \multicolumn{2}{|l|}{$(\mathrm{cc}) \mathrm{BY}$} \\
\hline \multicolumn{2}{|l|}{ Contents } \\
\hline 1. Introduction .................. & 52 \\
\hline 2. Materials and methods ....... & 53 \\
\hline 3. Results and discussion ...... & \\
\hline 4. Conclusions ................... & 57 \\
\hline References ................... & \\
\hline
\end{tabular}

\begin{abstract}
The article presents data on the effectiveness of new domestic antiparasitic drug "Insectostop for dogs and cats" in comparison to the reference drugs "Burdi Fipro for dogs" and "Burdi Fipro for cats" that is used for therapeutic and prophylactic purposes against ectoparasitosis of dogs and cats of different breeds. According to the results of the research, the parasitism of fleas of Ctenocephalus canis, C. felis and Pulex irritans species and parasitiform mites of the Ixodes ricinus and Dermacentor reticulatus species and sarcoptiform mites of the species Otodectes cynotis were detected on experimental animals. Clinically, this was inspected by redness, inflammation of the skin, itching reflex, the emergence of papules on the skin, scales. Based on the results, it was found that 8 hours after usage of the experimental drug "Insectostop for dogs and cats" its effectiveness in syphonapterosis of dogs was $87.9 \%$, and after usage of the reference drug "Bourdie Fipro for dogs" $-86.9 \%$, and in experiments on cats, the effectiveness of the experimental drug for siphonapterosis in cats was $92.4 \%$, and the reference drug "Bourdie Fipro for cats" $-90.3 \%$. Starting from the first and third days after usage of drugs on the fur of dogs and cats of the experimental and control groups, parasitological studies did not reveal fleas of the species Ctenocephalus canis, C. felis and Pulex irritans. So starting from the first day, the experimental and reference drugs showed $100 \%$ effectiveness during the siphonapterosis in dogs and cats. During the ixodidosis of dogs, it was found that at the 8-th hour after usage of the experimental drug "Insectostop for dogs and cats" its effectiveness was $82.9 \%$, and after usage of the reference drug "Bourdie Fipro for dogs" $-81.3 \%$. At the 24-th hour after usage of the experimental drug, its effectiveness was $97.6 \%$, and after usage of the reference drug $-95.9 \%$. At the 72 nd hour of the experiment, no adult representatives of the species Ixodes ricinus and Dermacentor reticulatus were found on the fur of dogs of these groups. Thus, at 72 hours after usage of the experimental and reference drug, they showed $100 \%$ efficiency on adult Ixodes mites. During the Otodectesis of dogs it was found that on the 7th day, effectiveness of the experimental drug was $75.6 \%$, on the 14th day $-98.1 \%$ and after usage of the reference drug "Bourdi Fipro for dogs" its effectiveness on the 7 th day was $73.5 \%$, and on the 14 th $-98.3 \%$. At 21 -st days after treatment of animals with drugs as a result of clinical examination and parasitological examination of dogs mites of the species Otodectes cynotis were not detected. In experiments on cats, on the 7 th day after usage of experimental drug, its effectiveness during Otodectesis of cats was $76.9 \%$, and after usage of reference drug $-77.1 \%$. As a result of clinical examination and parasitological study of the experimental and control groups of animals on the 14th day after treatment of the auricles of cats with mites of the species Otodectes cynotis was not detected. Thus, usage of both drugs promotes the release of Otodectesis in dogs from parasites on the 21 st day of the experiment, and cats - on the 14th day. Tests have shown that the experimental drug "Insectostop for dogs and cats" $(100 \mathrm{ml}$ of the drug contains the active substance: fipronil $-10 \mathrm{~g})$ does not cause skin irritation, dermatitis, seborrhea, allergic and other side effects, that the drug is well tolerated by dogs and cats and doesn't give any side effects and changes of clinical condition of animals.
\end{abstract}

Key words: parasitology, dogs, cats, siphonapterosis, ixodidosis, Otodectesis, the effectiveness of the drug.

\section{Citation:}

Tishyn, O. L., Yuskiv, I. D., Yuskiv, L. L., Perih, Zn. M., \& Bogach, O. M. (2021). The comparative evaluation of complex drugs based on fipronil for ectoparasitosis of dogs and cats. Ukrainian Journal of Veterinary and Agricultural Sciences, 4(2), 52-57.

\section{Introduction}

Nowadays there are many different forms of use of dogs and cats, one of which - the enrichment of the spiritual world of people. Number of domestic animals, in particular dogs and cats has increased significantly and the incidence of ectoparasitic diseases has increased accordingly. The most common causative agents of entomoses and acaroses of carnivores are fleas, hair flies, lice, parasitiformed and acariformed mites. Keeping carnivores in urban apartments adversely affects their physiological condition, including the condition of the skin and hair. Reports in domestic and foreign literature indicate that one of the current problems of animal owners (dogs, cats) and veterinarians is the patholo- 
gy of the skin of animals, which occurs due to parasitism of skin exo- and endoparasites (Hnilica \& Patterson, 2016; Craig, 2016; Rusr, 2017; ESCCAP, 2018). However, despite the large number of antiparasitic drugs offered by world and domestic veterinary science, they are not always properly used and used, because the treatment of dogs and cats, from skin exo- and endoparasites, long, often ineffective and expensive. So it is important to find the most effective treatments for permanent or temporary ectoparasites of animals. Insectoacaricides in the form of drops are quite easy to use, do not require much time, it is very convenient when handling aggressive animals. Also, this type of treatment is convenient for shelters, points of temporary keeping of animals that contains a large number of animals. This type of processing does not require certain skills and knowledge from the owner. Drops for spot application (purines) - one of the forms of insecticide treatments, they are applied to a limited area of the body, usually along the spine. During the day, drug spreads across the entire body and accumulates in the sebaceous glands of the skin without entering the bloodstream. The disadvantage of this form of treatment - possible irritation after application to the skin. The principle of their action is based on the absorption of the active substance from the skin surface into the subcutaneous layer. The active substance does not enter the blood: the drug is evenly distributed over the entire area of subcutaneous fat, deposited in the sebaceous glands and hair follicles. The active substance is gradually released on the skin surface in quantities that create the necessary concentration to protect against ectoparasites.

In recent years, manufacturers have offered a number of drugs, one of which is "Insectostop for dogs and cats" (veterinary drug for spot application in the form of drops) that is used for therapeutic and prophylactic purposes for ectoparasitosis of dogs and cats at all stages of parasites. The active substance of the drug fipronil is an ectoparasiticides belonging to the group of phenylpyrazole derivatives.

Fipronil affects the central nervous system of ectoparasites without affecting the central nervous system of dogs and cats. The mechanism of action is that the drug inhibits the passage of chlorine ions in GABA-dependent chloride channels by disrupting the nervous system. The usage of fipronil is caused by its contact and intestinal actions against parasitic individuals of different insect species (fleas, lice, hair flies), sarcoptiform and parasitic mites (Beugnet \& Franc, 2010; Linardi \& Santos, 2012).

The aim of the research was to conduct comparative studies to establish the insecticidal efficacy of the drug "Insectostop for dogs and cats" and reference drugs "Bourdie Fipro for dogs" and "Bourdie Fipro for cats" when used in the recommended doses for ectoparasitoses of dogs and cats.

\section{Materials and methods}

The research involved dogs aged 3 months to 6 years with a live weight of 5 to $40 \mathrm{~kg}$ and cats aged 6 months to 4 years with a live weight of 2 to $8 \mathrm{~kg}$ of different breeds, spontaneously affected by ectoparasites: fleas, parasitiformes and sarcoptiformes mites. The research was carried out in clinics of "Vetservice" LLC, Lviv and in the veterinary clinic of Dr. Markevich, taking into account the animals of the individual sector. In accordance to the general rules, based on clinical and parasitological studies, experimental and control groups of animals (6 dogs and 5 cats) was formed on the principle of analogues, where in the recommended doses used for ectoparasitic infestations experimental group drug "Insectostop for dogs and cats", and the control group - reference drugs "Bourdie Fipro for dogs" and "Bourdie Fipro for cats".

Parasitological researches on dogs and cats were performed by visual inspection and collection of biological material for laboratory testing for ectoparasites in accordance with GCP standards (VICH GL9, 2000), EU and WAAVP guidelines for testing and evaluating the effectiveness of antiparasitic substances for the treatment and prevention of lesions arthropoda (insects, mites) of dogs and cats (EMEA/CVMP/EWP/005/2000-Rev. 2, 2007; Marchiondo et al., 2013; EMEA/CVMP/EWP/005/2000-Rev. 3, 2016).

Before, during and after treatment of insect ectoparasites, ixode and otodectese mites, a clinical examination of the animals was performed. The intensity of flea and ixode mites infestation was determined by counting their number on the skin of the animal, and otodectese mites - by counting their number in the animal's ear.

The flea population on dogs and cats was assessed by visual counting on each animal and during the examination was combed with a fine-toothed comb all over the body for a specified time. Mites detected by inspection were removed from the skin of the animal with tweezers, and from the ears sampling was performed by smear. Identification of ectoparasitic pathogens was performed by microscopic method in accordance with practical guidelines (Yuskiv, 1998; Kramer \& Mencke, 2001; Taylor et al., 2016).

Experimental and control groups of animals drugs were applied with a pipette and a polymer ampoule on intact skin individually, externally (spot-on), once, and during Otodectesis by treating the skin of the inner surface of the shells in doses according to the manufacturer's recommendations.

After treatment of dogs and cats for sifonapterosis, ixodidosis, the effectiveness of the drugs was determined at 8 , 24 and 72 hours, and for Otodectesis at 7, 17 and 21 days.

The effectiveness of insectoacaricides was calculated using the formula Abbott: $\mathrm{t}(\%)=[(\mathrm{Amc}-\mathrm{Amt})$ : Amc $] \times 100$, where: $A m c=$ the arithmetic mean number of live insects / mites in the control group; Amt $=$ the arithmetic mean of live insects / mites in the treatment (experimental) group of animals.

All measures described in this study were carried out in accordance to the European Directive (Directive $2010 / 63 /$ EC) on procedures of the protection of animals used for scientific purposes.

The results were statistically processed in accordance to the principles of clinical trials for veterinary medicinal products minus arithmetic mean values $(\mathrm{M})$, root mean square error $(\mathrm{m})$ and the degree of probability of difference $(\mathrm{P})$, between indicators using the statistical software package Statystica 5.0 for Windows XP (CVMP/EWP/ 81976/2010, 2012).

\section{Results and discussion}

As a result of clinical examination and parasitological examination of dogs in veterinary clinics of Lviv on their body was found parasitizing fleas of Ctenocephalus canis and Pulex irritans species with an infestation intensity of 124 to 133 fleas per animal with an average infestation intensity of $128.7 \pm 0.86$ fleas per animal. Parasitological 
researches of dogs on presence of flea populations showed that in the experimental group of animals the intensity of infestation by ectoparasites of the species Ctenocephalus canis and Pulex irritans ranged from 124 to 132 fleas per animal with an average infestation intensity of $128.0 \pm 1.39$ fleas per animal, and in in the control group of animals, the intensity of invasion by insects-ectoparasites ranged from 126 to 133 fleas per animal with an average intensity of invasion of $129.3 \pm 1.0$ fleas per animal (Table 1).

After treatment of dogs with drugs according to the manufacturer's recommendations found in the experimental group of animals for 8 hours of study, reducing the intensity of infestation by ectoparasites Ctenocephalus canis and Pulex irritans from 124-132 to 14-17 fleas per animal at an average invasion intensity of $15.5 \pm 0.43$ fleas per animal, and in the control group of animals decreased the intensity of infestation by ectoparasites of the species Ctenocephalus canis and Pulex irritans from 126-133 to 16-19 fleas per animal with an average intensity of invasion of $17.3 \pm 0.49$ fleas per animal.

The results of our research show that at 8 hours after usage of experimental drug, its effectiveness during Siphonapterosis in dogs was $87.9 \%$, and after the use of the reference drug $-86.6 \%$ (Table 1 ).

Table 1

Efficiency of the drug "Insectostop for dogs and cats" and the reference drug "Bourdi Fipro for dogs" for Siphonapterosis of $\operatorname{dogs}(\mathrm{M} \pm \mathrm{m})$

\begin{tabular}{|c|c|c|c|c|c|c|c|}
\hline \multirow{3}{*}{$\begin{array}{l}\text { Groups of dogs } \\
\qquad(n=6)\end{array}$} & \multicolumn{4}{|c|}{ II, species of fleas on the body of animals } & \multicolumn{3}{|c|}{ Efficiency, \% } \\
\hline & \multirow{2}{*}{$\begin{array}{l}\text { Before } \\
\text { processing }\end{array}$} & \multicolumn{6}{|c|}{ After processing, hours: } \\
\hline & & 8-th & 24-th & 72-nd & 8-th & 24-th & 72-nd \\
\hline $\begin{array}{l}\text { Experimental group } \\
\text { "Insectostop for dogs and cats" }\end{array}$ & $\begin{array}{c}128.0 \pm 1.39 \\
(124-132)\end{array}$ & $\begin{array}{l}15.5 \pm 0.43 \\
(14-17)\end{array}$ & 0.0 & 0.0 & 87.9 & 100 & 100 \\
\hline $\begin{array}{l}\text { Control group } \\
\text { "Burdi Fipro for dogs" }\end{array}$ & $\begin{array}{c}129.3 \pm 1.05 \\
(126-133)\end{array}$ & $\begin{array}{l}17.3 \pm 0.49 \\
(16-19)\end{array}$ & 0.0 & 0.0 & 86.6 & 100 & 100 \\
\hline
\end{tabular}

Starting from the first and third days after the application of drugs on fur of dogs of experimental and control groups, parasitological studies did not reveal fleas of Ctenocephalus canis and Pulex irritans, ie drugs were $100 \%$ effective in Siphonapterosis (Table 1).

As a result of a clinical examination and parasitological examination of cats in veterinary clinics of Lviv on their body was found, by combing, parasitizing fleas species Ctenocephalus felis and Pulex irritans with an infestation intensity of 66 to 76 fleas per animal with an average infestation intensity of $70.2 \pm 1.05$ fleas per animal.

In addition, small black-brown crumbs of flea feces were observed on the white litter. The animals have itchy skin, the animals often itch.

Parasitological examinations of cats for the presence of flea populations showed that in the experimental group of animals the intensity of infestation by ectoparasites of Ctenocephalus felis and Pulex irritans species ranged from 66 to 72 fleas per animal with an average infestation intensity of $68.4 \pm 1.17$ fleas per animal, and in in the control group of animals, the intensity of invasion by insects-ectoparasites was, respectively, from 68 to 76 fleas per animal with an average intensity of invasion of $72.0 \pm 1.41$ fleas per animal (Table 2).

Our studies showed that after treatment of cats with drugs in the experimental group at 8-th hour found a decrease in the intensity of infestation by ectoparasites of Ctenocephalus felis and Pulex irritans species from 66-72 to 4-6 fleas per animal with an average intensity of flea ectoparasites $5.2 \pm 0.37$ fleas per animal, and in the control group of animals a decrease in the intensity of infestation by ectoparasites of Ctenocephalus felis and Pulex irritans species from 68-76 to 6-8 fleas per animal with an average intensity of flea ectoparasites of $7.0 \pm 0.45$ fleas per animal (Table 2).

The data obtained during the study show that at 8-th hour after usage of the experimental drug, its effectiveness during Siphonapterosis of cats was $92.4 \%$, and after the use of the reference drug $-90.3 \%$.

\section{Table 2}

Efficiency of the drug "Insectostop for dogs and cats" and the reference drug "Bourdi Fipro for cats" for cat Siphonapterosis $(\mathrm{M} \pm \mathrm{m})$

\begin{tabular}{|c|c|c|c|c|c|c|c|}
\hline \multirow{3}{*}{$\begin{array}{l}\text { Groups of cats } \\
\qquad(\mathrm{n}=5)\end{array}$} & \multicolumn{4}{|c|}{ II, species of fleas on the body of animals } & \multicolumn{3}{|c|}{ Efficiency, \% } \\
\hline & \multirow{2}{*}{$\begin{array}{c}\text { Before } \\
\text { processing }\end{array}$} & \multicolumn{6}{|c|}{ After processing, hours: } \\
\hline & & 8-th & 24-th & 72-nd & 8-th & 24-th & 72-nd \\
\hline $\begin{array}{l}\text { Experimental group } \\
\text { "Insectostop for dogs and cats" }\end{array}$ & $\begin{array}{l}68.4 \pm 1.17 \\
(66-72)\end{array}$ & $\begin{array}{l}5.2 \pm 0.37 \\
(4-6)\end{array}$ & 0.0 & 0.0 & 92.4 & 100 & 100 \\
\hline $\begin{array}{l}\text { Control group } \\
\text { "Burdi Fipro for cats" }\end{array}$ & $\begin{array}{c}72.0 \pm 1.41 \\
(68-76) \\
\end{array}$ & $\begin{array}{c}7.0 \pm 0.45 \\
(6-8) \\
\end{array}$ & 0.0 & 0.0 & 90.3 & 100 & 100 \\
\hline
\end{tabular}

Starting from the first and third days after usage of drugs on the fur of cats of the experimental and control groups, parasitological studies did not reveal fleas of Ctenocephalus felis and Pulex irritans, ie drugs showed $100 \%$ efficacy in Siphonapterosis (Table 2).

The obtained results allow us to conclude that the drug "Insectostop for dogs and cats" and the reference drugs
"Bourdie Fipro for dogs" and "Bourdie Fipro for cats" presented for research showed $100 \%$ effectiveness during Siphonapteroses invasion of dogs and cats.

As a result of clinical examination and parasitological examination of dogs in the veterinary clinic of Dr. Markevich on their body by examination of the skin, the parasitism was detected on the body surface of the animal 
imago parasitiformes mites species Ixodes picinus and Dermacentor reticulatus (Fig. 1 and 2). In the experimental group of animals, the intensity of infestation by mitesectoparasites was from 5 to 9 Ixode mites per animal with an average intensity of invasion of $7.0 \pm 0.58$ mites per animal,



Fig. 1. Ixode mites on the litter

After treatment of the skin of dogs with drugs at 8-th hour it was found that in animals of the experimental and control groups, the number of adult Ixode mites was in groups from 1 to 2 mites-ectoparasites per animal. In this experimental group, the average intensity of Ixode mites infestation was $1.2 \pm 0.17$ mites per animal, and in the control group $-1.5 \pm 0.22$ mites per animal.

The data obtained during the study show that at 8-th hour after usage of the experimental drug, its effectiveness during Ixodidoses of dogs was $82.9 \%$, and after usage of the reference drug $-81.3 \%$. At the 24 th hour of the experiment on the fur of one experimental dog, and in the control group of two dogs were found one viable Ixode mite.

In particular, at the 24th hour of the experiment after treatment, the average intensity of infestation by Ixode mites and in the control group of animals, the intensity of infestation by mites-ectoparasites ranged from 6 to 10 Ixode mites per animal at an average invasion intensity of $8.0 \pm 0.58$ mites per animal (Table 3).

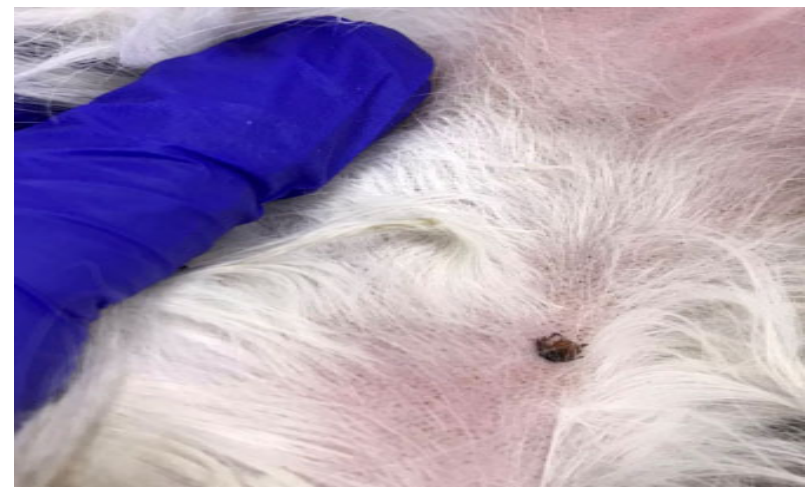

Fig. 2. Ixode mites on the dog's body

in the experimental group was $0.17 \pm 0.167$ mites per animal, and in the control group $-0.33 \pm 0.211$ mites per animal. After usage of the experimental drug, its acaricidal efficiency at 24 hours for Ixodidoses of dogs was $97.6 \%$, and after the use of the reference drug $-95.9 \%$.

During the parasitological study of animals at the $72 \mathrm{nd}$ hour of the experiment on the fur of dogs of the experimental and control groups were not found imago mites of the species Ixodes ricinus and Dermacentor reticulatus (Table 3).

Thus, at 72 hours after the use of the "Insectostop for dogs and cats" and the reference "Bourdie Fipro for dogs" in Ixodidoses Invasion, they were $100 \%$ effective on adult Ixodes ricinus and Dermacentor reticulatus.

Table 3

Efficiency of the drug "Insectostop for dogs and cats" and the reference drug "Bourdi Fipro for dogs" for Ixodidoses of dogs $(\mathrm{M} \pm \mathrm{m})$

\begin{tabular}{|c|c|c|c|c|c|c|c|}
\hline \multirow{3}{*}{$\begin{array}{l}\text { Groups of dogs } \\
\qquad(\mathrm{n}=6)\end{array}$} & \multicolumn{4}{|c|}{ II, species of Ixodes mites on the body of animals } & \multicolumn{3}{|c|}{ Efficiency, \% } \\
\hline & \multirow{2}{*}{$\begin{array}{l}\text { Before pro- } \\
\text { cessing }\end{array}$} & \multicolumn{6}{|c|}{ After processing, hours: } \\
\hline & & 8-th & 24-th & 72-nd & 8-th & 24-th & 72-nd \\
\hline \multirow{2}{*}{$\begin{array}{l}\text { Experimental group } \\
\text { "Insectostop for dogs and cats" }\end{array}$} & imago & $(1-2)$ & & & & & \\
\hline & $7.0 \pm 0.58$ & $1.2 \pm 0.17$ & $0.17 \pm 0.167$ & 0.0 & 82.9 & 97.6 & 100 \\
\hline \multirow{2}{*}{$\begin{array}{l}\text { Control group } \\
\text { "Burdi Fipro for dogs" }\end{array}$} & $\begin{array}{l}\text { imago } \\
(6-10)\end{array}$ & $(1-2)$ & & & & & \\
\hline & $8.0 \pm 0.58$ & $1.5 \pm 0.22$ & $0.33 \pm 0.211$ & 0.0 & 81.3 & 95.9 & 100 \\
\hline
\end{tabular}

As a result of a clinical examination and parasitological examination of dogs and cats in veterinary clinics, symptoms of otitis and dermatitis of the outer ear were revealed.

The intensity of infestation in dogs, by ear mites of the Otodectes cynotis species ranged from 7 to 12 mites per animal with an average intensity of invasion of $9.6 \pm 0.94$ ear mites per animal, and in cats the intensity of infestation by ear mites of the Otodectes cynotis species ranged from 2 up to 9 mites per animal at an average intensity of invasion of $6.1 \pm 0.83$ ear mites per animal (Fig. 3).

During the Otodectosis in sick animals observed: high intensity of invasion in the form of scabs and crusts, occupying more than $1 / 2$ of the surface of the auricle, inflammation of the outer ear, ear canal, eardrum, the appearance of puru- lent exudate with an unpleasant odor; medium intensity of invasion in the form of scabs and crusts of moderate thickness, which occupied $1 / 4-1 / 2$ of the auricle, severe hyperemia of the external auditory canal, increased local body temperature; low intensity of invasion in the form of hyperemia on the inner surface of the outer ear, the formation of otodectese crust, itching, scratching the paws of the ear. It should be noted that more severe forms of lesions of the auricles were observed in dogs.

Based on clinical and parasitological studies, two groups of animals were formed. In the experimental group of animals, the average intensity of infestation by ear mites of the Otodectes cynotis species was $9.0 \pm 0.97$ mites per animal, and in the control group of animals, the intensity of infesta- 
tion by mites of the Otodectes cynotis species was $10.2 \pm 0.91$ mites per animal (Table 4).

After treatment of dogs with skin medicines of the inner surface of the auricle in the experimental group of animals on the 7th day of study found a decrease of skin mites of the Otodectes cynotis species in auricles from 7-12 to 1-3 mites per animal at an average invasion intensity of $2.2 \pm 0.31$ mites per animal, and in the control group of animals reduction of skin mites of the Otodectes cynotis species in auricles from $7-12$ to $2-4$ mites per animal during an average intensity of invasion of $2.7 \pm 0.33$ mites per animal.
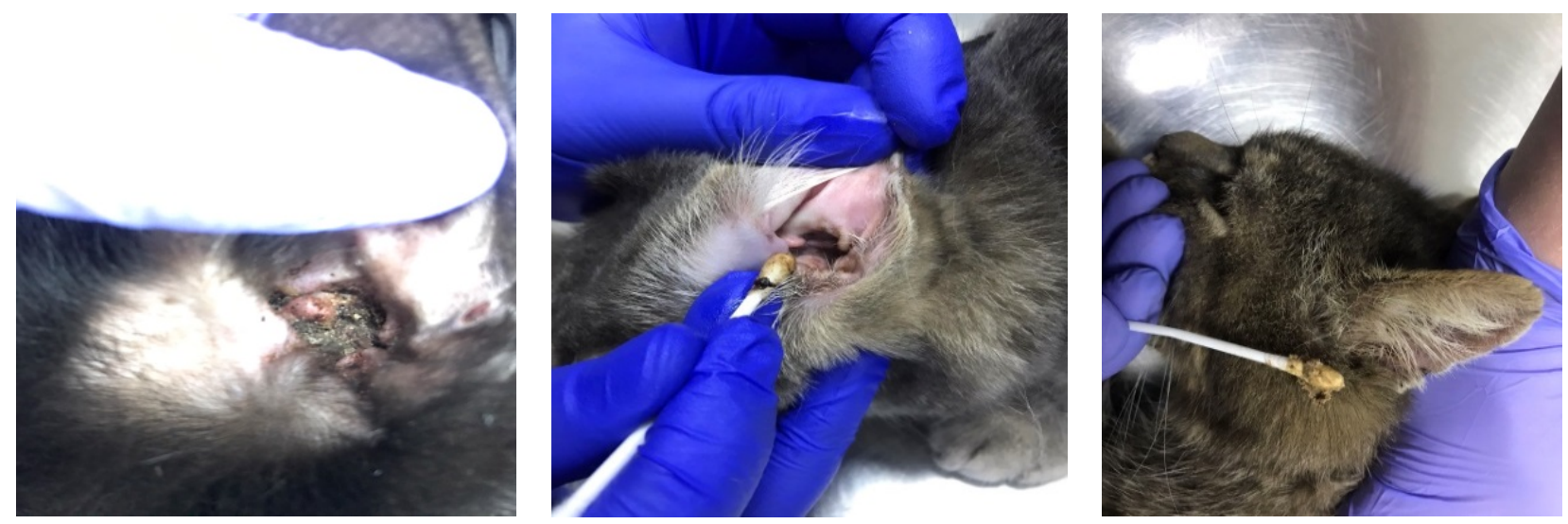

Fig. 3. Otodectes cynotis mite in a cat's auricle

Thus, on the 7th day after usage of the experimental drug "Insectostop for dogs and cats" its acaricidal efficiency for
Otodectosis in dogs was $75.6 \%$, and after usage of the reference drug "Bourdie Fipro for dogs" - 73.5 \% (Table 4).

Table 4

The effectiveness of the drug "Insectostop for dogs and cats" and the reference drug "Bourdi Fipro for dogs" for Otodectosis of $\operatorname{dogs}(\mathrm{M} \pm \mathrm{m})$

\begin{tabular}{|c|c|c|c|c|c|c|c|}
\hline \multirow{3}{*}{$\begin{array}{l}\text { Groups of dogs } \\
\qquad(\mathrm{n}=6)\end{array}$} & \multicolumn{4}{|c|}{ II, of Otodectes cynotis mites in the ears of the animal } & \multicolumn{3}{|c|}{ Efficiency, \% } \\
\hline & \multirow{2}{*}{$\begin{array}{c}\text { Before } \\
\text { processing }\end{array}$} & \multicolumn{6}{|c|}{ After processing, days: } \\
\hline & & 7-th & 14-th & 21-st & 7-th & 14-th & 21-st \\
\hline $\begin{array}{l}\text { Experimental group } \\
\text { "Insectostop for dogs and cats" }\end{array}$ & $\begin{array}{l}9.0 \pm 0.97 \\
(7-12)\end{array}$ & $\begin{array}{l}2.2 \pm 0.31 \\
\quad(1-3)\end{array}$ & $\begin{array}{c}0.17 \pm 0.167 \\
(0-1)\end{array}$ & 0.0 & 75.6 & 98.1 & 100 \\
\hline $\begin{array}{l}\text { Control group } \\
\text { "Burdi Fipro for dogs" }\end{array}$ & $\begin{array}{l}10.2 \pm 0.91 \\
(7-12)\end{array}$ & $\begin{array}{l}2.7 \pm 0.33 \\
\quad(2-4)\end{array}$ & $\begin{array}{c}0.17 \pm 0.167 \\
(0-1)\end{array}$ & 0.0 & 73.5 & 98.3 & 100 \\
\hline
\end{tabular}

During the parasitological examination on the 14th day after treatment of the auricles of dogs of the experimental and control groups, one mite of Otodectes cynotis was found in the auricles of one animal from the researched groups. In particular, in the experimental and control groups of dogs, the average intensity of infestation by mites of the species Otodectes cynotis was $0.17 \pm 0.167$ mites per animal. Thus, on the 14th day for Otodectosis after treatment of dogs with the experimental drug, its effectiveness was $98.1 \%$, and the effectiveness of the reference drug $-98.3 \%$.

On the 21 st day after processing of animals with drugs as a result of parasitological examination of ear mites of the species Otodectes cynotis in dogs was not detected. Present- ed for research drug "Insectostop for dogs and cats" and reference drugs "Bourdie Fipro for dogs" showed $100 \%$ effectiveness in otodectose invasion of dogs on the 21 st day of the experiment.

Parasitological studies of cats showed that in the experimental group of animals, the intensity of infestation by ear mites of the Otodectes cynotis species ranged from 2 to 7 mites per animal with an average intensity of invasion of $5.2 \pm 1.11$ mites per animal, and in the control group of animals the intensity of infestation ear mites of the Otodectes cynotis species ranged from 6 to 9 mites per animal at an average intensity of invasion $-7.0 \pm 0.55$ mites per animal (Table 5).

\section{Table 5}

The effectiveness of the drug "Insectostop for dogs and cats" and the reference drug "Bourdie Fipro for cats" for Otodectosis of cats $(\mathrm{M} \pm \mathrm{m})$

\begin{tabular}{|c|c|c|c|c|c|c|c|}
\hline \multirow{3}{*}{$\begin{array}{l}\text { Groups of cats } \\
\qquad(\mathrm{n}=5)\end{array}$} & \multicolumn{4}{|c|}{ II, of Otodectes cynotis mites in the ears of the animal } & \multicolumn{3}{|c|}{ Efficiency, \% } \\
\hline & Before & & & er pro & days: & & \\
\hline & processing & 7-th & 14-th & 21-st & 7-th & 14-th & $21-s t$ \\
\hline $\begin{array}{l}\text { Experimental group } \\
\text { "Insectostop for dogs and cats" }\end{array}$ & $\begin{array}{l}5.2 \pm 1.11 \\
(2-7)\end{array}$ & $\begin{array}{l}1.2 \pm 0.20 \\
\quad(1-2)\end{array}$ & 0.0 & 0.0 & 76.9 & 100 & 100 \\
\hline $\begin{array}{l}\text { Control group } \\
\text { "Burdi Fipro for cats" }\end{array}$ & $\begin{array}{c}7.0 \pm 0.55 \\
(6-9)\end{array}$ & $\begin{array}{l}1.6 \pm 0.24 \\
\quad(1-2)\end{array}$ & 0.0 & 0.0 & 77.1 & 100 & 100 \\
\hline
\end{tabular}


On the 7th day after treatment of the skin of the inner surface of the auricle of cats with drugs of the experimental and control groups, found from 1 to 3 mites of the Otodectes cynotis species in the auricles. In the experimental group, the average intensity of infestation by mites of the Otodectes cynotis species was $1.2 \pm 0.20$ mites per animal, and in the control group $-1.6 \pm 0.24$ mites per animal.

Data in table. 5 show that the acaricidal efficiency of the experimental drug "Insectostop for dogs and cats" for Otodectosis of cats was $76.9 \%$, and the reference drug "Bourdie Fipro for cats" - 77.1\%.During the clinical and parasitological examination of the experimental and control groups of cats on the 14th day after applying drugs on auricles, mites of the Otodectes cynotis species were not detected in the auricles. However, currently the study and reference drug have shown $100 \%$ efficacy in Otodectose invasion of cats.

Tests have shown that the experimental drug "Insectostop for dogs and cats" (100 $\mathrm{ml}$ of the drug contains the active substance: fipronil - $10 \mathrm{~g}$ ) does not cause skin irritation, dermatitis, seborrhea, allergic and other side effects, that the drug is well tolerated by dogs and cats and not gives no side effects and changes in the clinical condition of the animals.

Thus, the results show that the effectiveness of the drug "Insectostop for dogs and cats" in vivo in the treatment of the skin inaccessible for licking in the withers and along the spine once in field production tests during the infection of dogs and cats by ectoparasites flea-insects (Ctenocephalus canis, Ctenocephalus felis, Pulex irritans) and in dogs infected by parasitiformes mites (Ixodes ricinus, Dermacentor reticulatus) in the phase of adult imago, as well as treatment of the auricles in dogs and cats affected by ear mites (Otodectes cynotis) be $100 \%$.

\section{Conclusions}

1. Parasitological studies have shown that the experimental drug "Insectostop for dogs and cats" for external use "spot-on" is a highly effective insecticide against fleas Ctenocephalus canis, Ctenocephalus felis, Pulex irritans in dogs and cats.

2. The usage of "Insectostop for dogs and cats" drug individually, externally "spot-on", once against adult parasitic mites of Ixodes ricinus, Dermacentor reticulatus (syn. Dermacentor pictus) species at medium and high intensity of dog invasion promotes the dismissal of parasites from animals on the first day of the experiment. The usage of the "Insectostop for dogs and cats" drug individually, externally "spot-on" for the treatment of dogs and cats for Otodectosis helps to dismissal of parasites Otodectes cynotis from dogs on the 21 st day of the experiment, and cats on the 14th day.

3. Based on research of the "Insectostop for dogs and cats" drug it is established that the drug is well tolerated by dogs and cats and does not give any side effects and changes in the clinical condition of animals.

\section{Prospects for further research}

To study the antiparasitic efficiency of Ukrainian drugs based on other active substances in ectoparasitoses of dogs and cats.

\section{Conflict of interest}

The authors declare that there is no conflict of interest.

\section{References}

Beugnet, F., \& Franc, M. (2010). Results of a European multicentric field efficacy study of fipronil-(S) methoprene combination1 on flea infestation of dogs and cats during 2009 summer. Parasite, 17(4), 337-342. doi: 10.1051/parasite/2010174337.

Craig, M. (2016). Surface mites in dogs, cats and rabbits. Companion animal, 21(12), 678-684. doi: 10.12968/coan.2016.21.12.678.

ESCCAP (2018). Control of Ectoparasites in Dogs and Cats. Guideline 03 Sixth Edition, 1-34. URL: https://www.esccap.org/uploads/ docs/mjy50wev_0720_ESCCAP_Guideline_GL3_v9_1p.pdf.

European Medicines Agency, Committee for Medicinal Products for Veterinary Use, EMEA/CVMP/EWP/005/2000-Rev.2: Guideline for the testing and evaluation of the efficacy of antiparasitic substances for the treatment and prevention of mite and flea infestation in dogs and cats, 12 November 2007. London: European Medicines Agency; 2007. URL: https://www.ema.europa.eu/en/documents/scientificguideline/guideline-testing-evaluation-efficacy-antiparasiticsubstances-treatment-prevention-tick-flea_en.pdf.

European Medicines Agency, Committee for Medicinal Products for Veterinary Use, EMEA/CVMP/EWP/005/2000-Rev.3: Guideline for the testing and evaluation of the efficacy of antiparasitic substances for the treatment and prevention of tick and flea infestation in dogs and cats. URL: http://www.ema.europa.eu/docs/en_GB/document_library/Scie ntific_guideline/2016/07/WC500210927.pdf.

Hnilica, K., \& Patterson, A. (2016). Small Animal Dermatology 4th Edition. A Color Atlas and Therapeutic Guide. URL: https://www.elsevier.com/books/small-animal-dermatology/ hnilica/978-0-323-37651-8.

International Cooperation on Harmonization of Technical Requirements for Registration of Veterinary Medicinal Products. VICH GL9, Good Clinical Practice. London: European Medicines Agency; 2000. URL: https://www.ema.europa.eu/ en/vich-g19-good-clinical-practices.

Kramer, F., \& Mencke, N. (2001). Flea Biology and Control. Springer - Berlin - New York.

Linardi, P. M., \& Santos, L. (2012). Ctenocephalides felis felis vs. Ctenocephalides canis (Siphonaptera: Pulicidae): some issues in correctly identify these species. Rev. Bras. Parasitol. Vet., 21(4), 345-354. doi: 10.1590/s1984-29612012000400002.

Marchiondo, A. A., Holdsworth, P. A., Fourie, L. J., Rugg, D., Hellmann, K., Snyder, D. E., \& Dryden, M. W. (2013). World Association for the Advancement of Veterinary Parasitology. World Association for the Advancement of Veterinary Parasitology (W.A.A.V.P.) second edition: guidelines for evaluating the efficacy of parasiticides for the treatment, prevention and control of flea and tick infestations on dogs and cats. Vet. Parasitol., 194(1), 84-97. doi: 10.1016/j.vetpar.2013.02.003.

Rusr, M. K. (2017). The Biology and Ecology of Cat Fleas and Advancements in Their Pest Management: A Review. Insects, 118, 1-51. doi: 10.3390/insects8040118.

Statistical methodology, clinical trial design, veterinary medicinal product (VMP). CVMP/EWP/81976/2010. European Medicines Agency. $16 \quad$ January 2012. URL: https:/www.ema.europa.eu/en/documents/scientificguideline/final-guideline-demonstration-efficacy-veterinarymedicinal-products-containing-antimicrobial_en.pdf.

Taylor, M. A., Coop, R. L., \& Wall, R. L. (2016). Veterinary parasitology. - Wiley Blackwell. This edition first published.

Yuskiv, I. D. (1998). Akarologichni doslidchenna tvarin ta akaracidi. Navch.-prakt. pocibnik. Lviv, Kamenar. URL: https://www.researchgate.net/profile/Igor-Yuskiv-2/publication/ 327890520_Akarologicni_doslidzenna_tvarin_ta_akaricidi_Navc-

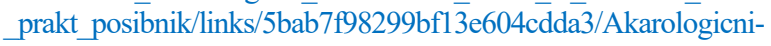
doslidzenna-tvarin-ta-akaricidi-Navc-prakt-posibnik.pdf (in Ukrainian). 